\title{
Discussion of Aviation Software Oversight Improvement
}

\author{
Marc Ronell \\ Aviation Safety Engineer \\ Aircraft Certification \\ U.S. Federal Aviation Administration \\ Burlington, MA, USA \\ mronell@riseup.net
}

\begin{abstract}
The paper describes and critiques the certification of U.S. aviation software. Flight-critical software certification and regulation need external academic review and intervention. Industry is driven to generate profits over prioritizing public safety concerns and has failed to develop adequately proven methods of certifying that flight-critical software is safe to deploy.

CCS Concepts: - Social and professional topics $\rightarrow$ Governmental regulations; Testing, certification and licensing; • Software and its engineering $\rightarrow$ Software safety; $\bullet$ Applied computing $\rightarrow$ Transportation.
\end{abstract}

Keywords: safety-critical software, aviation software, software requirements

\section{ACM Reference Format:}

Marc Ronell. 2020. Discussion of Aviation Software Oversight Improvement. In Proceedings of the 2020 ACM SIGPLAN International Symposium on New Ideas, New Paradigms, and Reflections on Programming and Software (Onward! '20), November 1820, 2020, Virtual, USA. ACM, New York, NY, USA, 12 pages. https://doi.org/10.1145/3426428.3426926

\section{Introduction}

Safety-critical software regulation is a topic that requires external review and attention from both academics and the

\footnotetext{
${ }^{*}$ Disclaimer: The opinions expressed in this paper are the views of the author and do not reflect the official policy or position of any agency of the U.S. government. This paper is dedicated with gratitude to Ms. Reality Winner, an American dissident. The paper is also in memory of the victims of the Boeing 737 Max accidents.

Permission to make digital or hard copies of all or part of this work for personal or classroom use is granted without fee provided that copies are not made or distributed for profit or commercial advantage and that copies bear this notice and the full citation on the first page. Copyrights for components of this work owned by others than ACM must be honored. Abstracting with credit is permitted. To copy otherwise, or republish, to post on servers or to redistribute to lists, requires prior specific permission and/or a fee. Request permissions from permissions@acm.org.

Onward! '20, November 18-20, 2020, Virtual, USA

(c) 2020 Association for Computing Machinery.

ACM ISBN 978-1-4503-8178-9/20/11 ..\$15.00

https://doi.org/10.1145/3426428.3426926
}

public. There is an immediate need to provide strong oversight of the U.S. Federal Aviation Administration's (F.A.A.'s) programs to review aviation company software before the applicants deploy their code into public aircraft. A functioning U.S. regulatory system is the public's best hope for reliable and safe travel, but any system created will need constant public supervision from a uniformly well-educated citizenship. Unfortunately, public aviation lacks an effective and clinically supported approach to certifying safetycritical software products. The F.A.A. uses a software review process that was not proven effective through empirical evidence. Worse, the agency's stewardship is tainted by various forms of corruption and inappropriate influence from the very companies and corporations that the agency is charged to oversee. $[4,7,16,20,31,47]$

\subsection{Regulators Need Public Support}

As the U.S. transportation systems become systemically less safe, and often detrimental to the U.S. lower economic strata, a wide variety of negative public consequences are degrading the U.S. standards of health and public safety. Poor neighborhoods have been made worse by highway projects that bypass their best interests. Industry has achieved a level of "regulatory capture in which the airline industry [manufacturers] openly dictates to its regulators its governing rules, arranging for not only beneficial regulation but placing key people to head these regulators...The people regulating the ... industry largely come from that industry or look to that industry for their social interactions." [50] Installing regulators to provide industry supervision fails once corporations gain influence over the regulators and their management. Attempting to install oversight over the regulators leads to a recursive path without an ending condition. Regulators cannot rely on the whistle-blower and U.S. Equal Employment Opportunity Commission (EEOC) programs for relief against the tendrils of corporate corruption. Worse still are the extremely limited elected representative resources. Even if the influence of corporate campaign contributions does not capture a regulator's one U.S. Congressperson and two U.S. Senators, elected representatives are stretched much too thin to police individual corporate and government offenders. A hypothetical honest regulator 
has no support or protection from the depth and reach of corporate pressure and the industry's government collaborators. New innovative approaches to industry and government stewardship are in the best interests of the flying public.

So why bring all this up at a software conference? Orville and Wilbur Wright succeeded, where most of their contemporaries failed, by following Wilbur's strict adherence to the rigorous scientific method applied as steps from existing glider and bicycle technology. [33] Today's aircraft certification is subdivided into disciplines. The reviewers are listed as mechanical, air-frame and structures, propulsion, and systems and electrical. Flammability is generally joined with structures. The agency does not consider software to be its own discipline. There are minimal software reviewers with academic credentials in the field. Software reviews, when performed at all, are typically given to the electrical and systems discipline. Software and network security have been, at best, an afterthought once the primary software functionality verification is complete. Under the current administration, the U.S. aviation leadership, following the national stance, holds the scientific method and academics in disdain. [8, 19, 41]

\subsection{Software Regulation is not Effective}

Pilots, afraid that software engineers will automate their jobs, are overcompensating by demonstrating a negligent indifference to software certification. Unnecessary accidents and deaths result from basic requirements mistakes. Imagine complicated aircraft engines being developed and thrown into service with no viable external software oversight for years - all under the careful auspices of the U.S. Department of Transportation. F.A.A. managers have repeatedly claimed that anyone who can read and follow the F.A.A. Orders and guidance can certify flight-critical software. "Under the delegation program, "the staff responsible for regulating aircraft safety are answerable to the manufacturers who profit from cutting corners, not the American people who may be put at risk," [said] Senator Richard Blumenthal, Democrat of Connecticut..." [28] Do you think the taxes you pay to protect you and your loved ones are actually used to accomplish that task? [38]

F.A.A. employees who attempt to warn the public or even cooperate with official investigations regarding the failure of F.A.A. oversight of aircraft certification expect retaliation. "Of particular note, our interviews of 15 employees found that 9 feared retaliation and 7 requested confidentiality (including some who requested to be interviewed off-site) because of a fear of retaliation." [45]

\subsection{Paper Overview}

First, in Section 2, the paper provides background on aviation accidents related to software and data problems. Next, in Section 3, the paper reviews software certification at the
U.S. F.A.A. for flight-critical software. F.A.A. training is described in Section 4. The U.S. Code of Federal regulations related to software certification is presented in Section 5. After the status quo is described, our conversation can move to a re-imagined software certification approach in Section 6. The discussion also must spotlight topics that need academic research and methods that have to be qualified and justified by empirical data. The paper ends with conclusions in Section 7.

\section{Background}

Section 2 provides a set of aviation software failures and incidents. Two sample incidents are examined. The Lufthansa flight LH 2904/14 to Warsaw Poland accident is reviewed in subsection 2.2 and the Irish Coast Guard Rescue 116 accident at Black Rock is described in subsection 2.3.

\subsection{Aviation Software Failures are not Rare}

A common misconception is that software accidents and mishaps in aviation are rare. A quick review of public literature reveals a history of fatal accidents resulting from software failures. [55] Daniel Jackson has a sample survey of some fatalities and investigated incidents related to software mistakes and improper configuration in his cited paper. [27] The survey lists the following investigation reports and articles. [2, 3, 6, 21, 39] Dr. Peter Ladkin of Bielefeld University has compiled a compendium of aviation softwarerelated accidents and incidents on his website. [29]

\subsection{Lufthansa Flight LH 2904/14 to Warsaw Poland}

Lufthansa flight LH 2904/14, an Airbus model A320-211, was attempting to land in Warsaw Poland on September 14, 1993, in bad weather. [30] The aircraft was equipped with "...an interlock intended to prevent the pilot from activating reverse thrust while airborne. Unfortunately, the software had been designed to meet a requirement that reverse thrust be disabled unless wheel pulses were being received (indicating that the wheels were turning and thus in contact with the ground). Because of rain on the runway, the aircraft aquaplaned when it touched down, and the wheels did not turn, so the software dutifully disabled reverse thrust, and the aircraft overran the runway." [26] As a result of the crash, "one crew member and one of the passengers lost their lives. The aircraft sustained damage caused by fire." [30] Table 1 points out some potential life-changing injuries, whereas news accounts generally only list the deaths. Babies are still not required to be in child restraint systems (seats).

\subsection{Irish Coast Guard Rescue 116 Helicopter Accident}

The Irish Coast Guard Rescue 116 helicopter accident that struck Black Rock off the Mayo coast in 2017 is another example of software contributing to an aircraft accident. 
Table 1. Injury profile of Lufthansa flight LH 2904/14, Warsaw 09/14/1993 [30]

\begin{tabular}{lc} 
Affected Area & No. wounded \\
\hline spine injuries & 21 \\
head injuries & 8 \\
chest injuries (broken ribs) & 8 \\
abdomen contusions & 4 \\
broken limbs & 5 \\
burns & 1 \\
other & 9
\end{tabular}

Honeywell's navigation equipment not only contained incomplete terrain data, but the gear did not warn pilots that the region was not sufficiently mapped. Concerning Black Rock and its lighthouse, the equipment manufacturer informed the Investigation that "The lighthouse obstacle is not in the obstacle database and the terrain of the island is not in our terrain database ... Honeywell's terrain data is sourced from our supplier [named supplier]. It is a digitized topographic map derived data set. It does not include Black Rock. We have looked at alternate sources, including SRTM and ASTER. While Black Rock is present in these alternate data sets, the actual altitude of Black Rock is considerably higher than what is indicated in these alternate data sets. Our obstacle data for the Ireland region is sourced from our Type 1 Letter of Acceptance (LOA) supplier, [named supplier]. This data is originated from the [named source] and does not include obstacles on Black Rock." [18, 23, 24] "There were two reports, in 2013 and 2015, that stated the maps were inaccurate, and nothing was done about it." [5] Captain Cullen identified the union's main concerns, citing "everything from flight time limitations to tiredness, the navigational inaccuracies, and security issues that are separate to safety." [54] If the terrain is not verified, the equipment must warn pilots and prevent the operator from engaging the autopilot system. The helicopter in this accident was reported flying in stable level flight at $200 \mathrm{ft}$ Radio Altitude, and Seventy-five knots Indicated Airspeed headed home. That is fast and low, skimming the water. Further analysis of this accident is found in Subsection 6.9.

\subsection{Freedom of Information Act (FOIA) Requests}

F.A.A. software review reports and documents may be available through the Freedom of Information Act (FOIA) process, but due to the proprietary nature of the software under review, one can anticipate significant redaction. Most reviewed documents are company proprietary as is virtually all aviation software. FOIA requests on the Boeing 737 Max accidents seem to be delayed directly by administration political appointees following revisions to FOIA regulations that were published by the Environmental Protection Agency without a public comment period. [22]

\section{Current Aircraft Software Certification}

Section 3 describes the current approach to software certification at the F.A.A. The material gives a brief overview of the software certification process.

\subsection{RTCA DO-178x Standard}

The F.A.A. theoretically certifies software in aircraft avionics systems (e.g., auto-pilots, fleet management systems, displays), flight control computers, and engine controls. F.A.A. software certification follows a Radio Technical Commission for Aeronautics (RTCA) standard DO-178x [42-44] that is also used by the international aviation community.

\subsection{What is Certification?}

Certification, in general, is a process that defines 1 . objectives to be achieved, 2. evidence supporting that an objective is satisfactorily attained. The applicants must collect and maintain their evidence that can be reviewed during an audit.

\subsection{Software Design Assurance Levels}

To some degree, the rigor of software certification is divided into levels based on the software's criticality. Generally, the most critical software system gets the most substantial review. Software failure condition categories are subdivided into 5 Design Assurance Levels (DAL):

1. Catastrophic - failure causes an immediate accident. (Level A)

2. Hazardous - failure causes a substantial reduction in safety margin. (Level B)

3. Major - failure reduces the crew's ability to handle hazards. (Level C)

4. Minor - failure does not significantly reduce the crew's ability to handle hazards. (Level D)

5. No Effect - failure does not impact operational capability. (Level E)

\subsection{Software Development Environment Tools}

The F.A.A. attempts to certify an applicant's software development environment and tools. The standard requires that applicants maintain the following as part of their software development environment:

- Bug Tracker

- Configuration Management Repository

\subsection{Software Architectural Safety Strategies}

The repositories are used to store software and document revision histories. Applicants for certification often use the following software architectural safety strategies: 
- Partitioning - isolation usually by separating memory.

- Dissimilar Software

- 2+ independently developed components; same functionality.

- Safety Monitoring - monitor function for failure

- Example: Server fail-over heartbeat monitor.

\subsection{The Software Lifecycle}

F.A.A. software audits examine what the agency refers to as properties of the Software Life Cycle. The Software Life Cycle is deconstructed into the review of Software Planning documents, Software Development and Software Verification.

The Software Planning documents key elements are similar to a graduate thesis. The applicant writes an initial document that says basically what the applicant intends to do and accomplish to create their software following the DO$178 \mathrm{x}$ and other select guidance. The applicant plans identify a source code repository to be used for the project. The document will also identify the planned verification and testing approaches. Typically the initial software document describes how the applicant intends to meet software quality assurance goals. For example, the applicant generally cites adherence to a software coding standard. Based on this initial software project proposal, the applicant then proceeds to generate both its software and documentation to satisfy the agency. Once the development and testing phases are complete, the applicant writes a final report that effectively says, "We followed our initial plan as laid out except in the following locations and sections." Those deviations are then described in the project Software Accomplishment Summary (SAS).

In addition to the documentation reviews, F.A.A. audits also examine the Software Development phase. The software development phase is divided into the potential examinations of four areas:

- Requirements

- Design aspects

- Software Coding

- Integration/Verification

\subsection{Software Regulators Lack Academic Training}

The "F.A.A. does not have the resources to oversee all [certification applicant] development..." [45] It is not surprising that F.A.A. auditors typically have no formal education in software development beyond an introductory first-year engineering course. The first-year programming courses presented function calls and loops that the auditor took at a University as an undergraduate 15-20 years ago. Most software reviewers graduated with electrical engineering degrees. They have no formal education in algorithms, programming language theory, or operating systems. Writing a functioning program is not a realistic expectation of the vast majority of F.A.A. auditors. Now they may be called upon to review safety-critical software. The vast majority of reviewers cannot distinguish a software algorithm from a heuristic. Even worse, industry coders are typically not much further along. While our society requires that physicians be state board certified and undergo regular and meaningful continuing medical education courses annually, our software auditors are not similarly qualified. Management supervising F.A.A. regulators does not have academic software backgrounds, and some have no more than a high school degree. Remember that these auditors are certifying flight-critical software.

\subsection{F.A.A. Tracing Activities}

With that background in mind, the auditors are asked to review software requirements. Auditors generally do not check for side effects or whether requirements are complete or even correct. At best, F.A.A. software auditors spot check to ensure that some random requirements are implemented in the software code. Matching requirements to code is referred to as tracing the requirements to code. Random code snippets are also traced back to their requirements. The F.A.A. certification approach does not mention or check a software specification. Also, when Visual Programming methods are employed, the code schematic is regarded to be the software requirements. Applicants using Visual Programming feed their schematics into an auto-code generator to create the source code. This approach is applied to all safety levels of software development. Reading through a schematic whose signal lines can span pages is challenging. Finding side effects, intended or otherwise, is also complicated at best.

\subsection{Ensure Requirements, Code and Verification Tests are Tightly Coupled}

All requirements are expected to have an associated functional verification test. Auditors should be able to trace all verification tests to the code that they verify. That code should then trace back to low and high-level requirements. A significant part of the on-site software audits involve tracing requirements to code implementations and on to verification tests. Random spot checks also trace verification tests back to code implementation and then back to requirements. The applicant's verification test developers are required to be individuals who are independent of the code developers. Tediously tracing requirements does not begin to catch the broader concerns. At most, tracing finds a localized problem but does not extend to finding the global concerns with reviewed code. Tracing is somewhat analogous to applying a hill-climbing algorithm. Significant problems not near the initially found faults may not be detected. Current software oversight does not examine a more comprehensive system 
perspective at on-site software audits. There is just a localized, mechanical review with a limited scope.

\subsection{The Software Design and Coding Phase}

The DO-178x guidance describes a Software Design phase. The phase is identified as refining objectives from high to low-level requirements. Auditors, when tracing requirements to the corresponding code, will step through the lower-level requirements. This Software Design phase just seems to be an extension of the Requirements phase. As part of the code review, some auditors will check to ensure that selected software code standards are implemented.

The Software Coding phase is expected to implement the low-level requirements. All code must trace to low-level software requirements, and all requirements must trace to code. Auditors randomly select code snippets and trace them back during audits.

In summary, DO-178x guidance attempts to certify that the development environment meets specific criteria. The software can fulfill all of the DO-178x objectives and still be lethal. For the most part, the guidance requires very rudimentary software development items, including configuration management tools, bug trackers, traceability, and verification. The F.A.A. does not require auditors to be academically trained in software theory.

\section{F.A.A. Software Training}

Section 4 describes F.A.A. software training. This section looks at the facilities and some training concerns. The F.A.A. runs a center for its Air Certification personnel in Oklahoma City that is intended to provide technical and management training. There is anecdotal evidence from F.A.A. training venues of problems with the quality of their pedagogy. [40]

\subsection{The F.A.A. Academy in Oklahoma City}

The agency refers to the training center for Aircraft Certification as its F.A.A. Academy. Management implies that F.A.A. courses prepare their employees to certify software. In a period of U.S. history where organizations such as University of Phoenix and Trump University have marketed themselves as academic institutions, concerns with the F.A.A. Academy should not be surprising. In my opinion, the F.A.A. Academy misuses government funds and risks the public by not adequately preparing its charges to certify flight-critical software. A two-week course at the F.A.A. Academy in no way substitutes for a four-year computer science degree at a trusted U.S. academic institution. Conversely, I have never seen the agency take a random inexperienced candidate and put that individual in a two-week pilot training course and then expect the individual to go out and flight test a new helicopter. Taking students who lack academic software credentials, sending them to the F.A.A. Academy for software training, and then releasing them to certify flight-critical software is criminally negligent. F.A.A. management that lacks software academic degrees have no business claiming to be able to judge the capabilities of their Academy.

\subsection{Economic Regional Booster}

From my experience, the F.A.A. Oklahoma Academy's real purpose is to boost the Oklahoma City business community economically. The school draws an endless stream of F.A.A. air certification employees to fill surrounding hotels and restaurants. A consequence of the economic stimulus program is potentially endangering the aviation impacted public. The Oklahoma training facility and its management are worthy of an investigation, at least in terms of its software training and preparation. There is a similar Florida based management training school. An instructor in the Florida management school summarized the entire F.A.A. academic program using a cliche she delivered as part of her lesson. At the F.A.A., "It is not what you know; it's whom you know." [25] Unfortunately, that is true not just for the Florida management curriculum but also for the Oklahoma technical training classes.

\subsection{Software Buzzwords}

The F.A.A. Academy's mission of training individuals who certify flight-critical software for passenger flights is a nontrivial assignment. Most Universities do not attempt to step up to this task. Instructors are given slide sets and materials by the Academy's administration to deliver to their classes. Instructors do not have the authority to present their own material or deviate to correct mistakes. They parrot the materials provided. The courses I have attended depict slides of buzzwords that are occasionally explained contrary to standard academic models or practice. In its programmable hardware course, the agency refers to reconfigurable logic as custom microcode. Outside of the F.A.A., microcode [1] refers to register transfer language (RTL). Assembly language instructions can be composed of RTL. Programmable logic is generally a fabric of configurable logic gates and functional units. Visual programming [9-12] within the F.A.A. is renamed as model-based development. A database within the F.A.A. does not loosely refer to a relational database management system (RDBMS) but instead really refers to the file-system data-file. [46] The data-file is typically accessed directly by applications without the benefit of an RDBMS to protect and help maintain the integrity of the data while simultaneously speeding up access through indexed lookups. The agency's stated goal of ensuring that aeronautical databases "remain current and valid" [46] seems to fail fairly regularly with lethal results. $[5,24,54]$ The Academy course materials give the impression that the authors searched for and strung together buzzwords and jargon to develop their lessons sometimes with dubious results. 


\subsection{Essential Software Topics are Missing}

Essential software topics such as algorithms, programming language theory, and operating systems are not covered in depth at the Academy's software related courses. Although the DO-178x guidance requires that software algorithms be accurate, there is no training to prepare students to make that determination. Evaluating whether a particular algorithm is a good fit for its application requires knowledge of a variety of algorithms. The F.A.A. Academy, in its 2-week course, needs to cover all of software for non-majors. Algorithms and other software topics are not covered in sufficient depth to regulate safety-critical software. Software performance and software profiling were not discussed to a level that would allow a student to find compliance during an audit if the topics were covered. DO-178c refers to recursion. The software training does not adequately explain software recursion, its impact on the process stack, and how to regulate the paradigm.

\section{Software Regulations}

Section 5 describes the U.S. Code of Federal Regulations that apply to aviation software certification.

\subsection{Aircraft and Helicopter Regulations}

There are practically no regulations related to software in the U.S. Code of Federal Regulations for aviation. Most software compliance is levied against the Code of Federal Regulations (CFR) rules 1301 and 1309 for parts 23, 25, 27, and 29. These parts define the regulations for small or general aviation aircraft (Part 23), transport category aircraft (Part 25), and helicopters (Part 27 \& 29). General aviation includes smaller, often privately owned personal aircraft. Transport category aircraft are used for commercial aviation and includes aircraft developed by Boeing and Airbus. Part 27 describes smaller sized helicopters such as those manufactured by Robinson. Part 29 describes larger helicopters such as those manufactured by Sikorsky.

Regulation 1301, as in 23.1301, 25.1301, 27.1301, and 29.1301, require that equipment installed on an aircraft perform its intended function and behave properly when installed. The regulation is not specific to software and equally applies to onboard galley appliances.

Regulation 1309 similarly requires equipment, systems, and installations to perform their intended function under foreseeable operating conditions. This regulation is again not software specific and applies to a wide variety of onboard equipment.

\subsection{Engine and Propeller Regulations}

Although small aircraft, helicopters, and transport category vehicles lack software regulations, engine and propeller regulations in parts 33 and 35 respectively do at least mention software. The software in these aircraft components is safety-critical.

- Part 33 Aircraft Engines Sec. 33.28 Amdt. 33-26, Eff. 10/20/08 Engine control systems (g) Software. The applicant must design, implement and verify all associated software to minimize the existence of errors by using a method, approved by the F.A.A., consistent with the criticality of the performed functions.

- Part 35 Propellers Sec. 35.23 Amdt. 35-8, Eff. 12/23/08 Propeller control system. (c) Electronic propeller control system embedded software must be designed and implemented by a method approved by the Administrator that is consistent with the criticality of the performed functions and that minimizes the existence of software errors.

\subsection{Special Conditions}

The F.A.A. can create a special condition regulation that applies to a particular aircraft design. Special conditions are infrequently generated if the agency determines that existing regulations do not cover an unusual or novel design feature of an aircraft. There are times when the agency issues special conditions related to software. Software is not a new or novel aspect of aircraft, engine or propeller design and must be covered by the U.S. Code of Federal Regulations. Using Special Conditions to fix gaps in the regulations wastes valuable oversight resources.

\subsection{Elements Missing from the Regulations}

All legal sections lack seemingly distinct and critical software regulations. No regulations require that software systems log warning and error messages with a universal time coordinate stamp maintained to a specific minimum resolution. Error messages can provide warnings that hardware needs replacement or maintenance attention. No regulations require that computer data and network security precautions be implemented, protecting the aircraft's operation and integrity. Requiring all design assurance level A, B, and $\mathrm{C}$ software to be written as non-proprietary, free code would increase code transparency. There is a significant number of software areas that should be regulated for essential maintenance and operations. It seems to defy explanation that software as a discipline has been neglected to become an obvious threat to public safety. There are not enough staff in decision making positions with academic training in software to advocate for public safety related to software regulation. 


\section{Considerations for Improvement}

Section 6 reviews some potential concepts that could be applied to improve the efficacy of agency regulation. Safetycritical software lacks strong and effective oversight.

\subsection{Public Oversight of the Agency Required}

Fixing the problem with software certification is most likely a challenging, long term project. The main concern is that oversight failures are not rising to the attention of the flying public that is most threatened by the inadequacies. The F.A.A. is intended to provide supervision of the aviation industry. Requiring stewardship of the F.A.A. that itself is charged with providing oversight to industry highlights the level of failure involved and the need for reform. Worse, the F.A.A. often acts as an economic booster and lobby group for the aviation industry, wasting and diverting vital regulatory resources. "The F.A.A. is unusual among federal agencies because it was originally established to regulate and promote an industry...the imperative to "foster air commerce" got top billing in the [F.A.A.'s] charter language." [36] "The tragic crashes of Boeing 737 MAX airplanes have, once again, reminded the public of the dangers of regulatory capture and industry "self-regulation." While many were shocked to learn that the Federal Aviation Administration (F.A.A.), our government's primary airline safety regulator, essentially handed over its responsibility to certify that airplanes are safe to the manufacturers of those planes, the reality is that this model of industry self-regulation is the norm, not the exception." [38] "All anyone has to do is look at the revolving door in Washington, DC, [ as F.A.A. executives move between the agency, industry lobbies, and corporations ] ... to realize that there is a cozy relationship. Now the question is: Is that cozy relationship harming the safety decisions being made? ... In the case of the 737 Max, the answer appears to be a resounding yes." [51]

\subsection{Audits Must Trace Software Requirements to the FHA and PSSA}

An example of additional checks that seem to be missing during software audits would include ensuring that software requirements trace to the concerns identified in Functional Hazard Assessment (FHA), the Preliminary System Safety Assessment (PSSA) and the System Safety Analysis (SSA). The FHA, PSSA, and SSA are defined in the Society of Automotive Engineers (SAE) documents ARP4754 and ARP4761 [48, 49] and are part of the aircraft assessment. The ARP4754 and ARP4761 "describe guidelines and methods of performing a safety assessment for the certification of civil aircraft." The FHA, PSSA, and SSA documents are not typically reviewed during software requirements audits. The FHA, PSSA, and SSA are defined as:
- Functional Hazard Assessment (FHA) - aircraft functions are classified according to the severity of their failure conditions.

- Preliminary System Safety Assessment (PSSA) - identifies protective strategies, considering fail-safe concepts and architectural attributes that may be required.

- System Safety Analysis - shows that relevant safety requirements are met.

\subsection{Preliminary System Safety Assessment (PSSA)}

The PSSA, by definition, "should identify and capture all derived system safety requirements (e.g., protective strategies such as partitioning, built-in-test, dissimilarity, monitoring, safety-related tasks and intervals). The PSSA outputs should be used as inputs to the SSA and other documents, including, but not limited to, system requirements, hardware requirements, and software requirements." [49] When the F.A.A. reviews software, the audit must check the code requirements ensuring that they cover all of the relevant safety requirements identified in the PSSA. Further, the F.A.A. audits can ensure that requirements defined in the PSSA correspond to related failures in the FHA and that all potentially relevant software-related concerns identified in the FHA are covered by requirements identified in the PSSA. Elevating the audits to examine the linkage between the software requirements and the PSSA, FHA and SSA could help establish a more meaningful review of the software requirements. Requirements reviews can be expected to necessitate a cross engineering disciplinary team. Software requirements in the PSSA must be categorized, DAL ranked and clearly distinguished from non-software requirements. The value of software requirement reviews that follow linkages into the FHA, PSSA, and SSA documents and ensure coverage needs to be verified by external independent clinical research. Empirical research needs to determine what parts of software oversight provide the most significant safety gains. We need experiments to determine the software development process locations whose inspections provide significant safety improvements.

\subsection{Software Architectural Mitigations}

Dissimilar software, described in Section 3 as an example of an architectural safety strategy, must be studied carefully by a qualified academic research organization. The trade-offs between attempting to develop two different versions of software versus just concentrating on debugging and optimizing one version are not clear. Clinical research is needed to explore how bug trackers, source code repositories, and architectural mitigation techniques improve code quality and accuracy. Perhaps some applications of these 
techniques give better results or produce no definitive improvement to software generation. Answering these questions via clinical experiments may need a new level of serious research funding commitment from the government. There may need to be new approaches to software research beyond the current industry and academic research grants.

\subsection{Classify Requirements}

Software developers must categorize and classify their requirements according to their design assurance levels (DAL). The requirements classification must link back to the FHA and PSSA. That will allow an auditor to concentrate more of their review on the requirements considered to be safetycritical. Currently, the guidance does not require that requirements be categorized according to safety level criteria.

\subsection{Embed Journalists}

Instead of generating new layers of supervision on the F.A.A. that can again be captured by the aviation industry, new approaches may lead to better results. The federal government must fund academic research to find and test oversight solutions that provide a reliable public benefit. Perhaps embedding journalists within the agency on multi-year rotations to monitor and report on transportation topics, including supervision concerns, could help not just solve the stewardship problems but also advance the cause of aviation safety, stimulate student interest in aviation, and highlight legal concerns. The government/journalist partnership could help provide stimulus to support media outlets. Prize committees can award additional rotating journalism grants for journalistic excellence. The embedded correspondents could keep both the public and government officials informed about concerns within oversight agencies similar to the F.A.A. Keeping the aviation industry from exercising inappropriate influence over journalists needs significant consideration.

\subsection{Connect Regulators and Surviving Family}

In my personal experience, working as a regulator feels vaguely like serving as a teacher in a Stanley Milgram experiment. [34, 37] In his introduction to our job, our manager emphasized that we would not be held liable for any accidents resulting from our decisions and reviews per the U.S. Supreme Court's Varig [14] decision as long as we gave the impression that we spot-checked certification submissions. As regulators, we are separated and protected from our learners and the consequences of our actions. Our job is obedience to our management. [45] A fundamentally positive change would be to destroy the wall between learner and teacher and require regulators to periodically meet with the surviving family members of those lost due to aviation accidents in a structured, mediated environment.
Calls for modern police reform request the end of the doctrine of qualified immunity that grants government officials performing discretionary functions immunity from civil suits. Qualified immunity is a form of sovereign immunity that must be addressed, as discussed in Subsection 6.12. All forms of sovereign immunity that protect regulators and their managers from surviving family members must be removed. Although challenging, there is an impressive potential benefit in humanizing those who have experienced loss and giving them the chance to impress on regulators the importance and diligence that must be applied to safetycritical software reviews.

At accident hearings with surviving family members, the FAA must provide the families of accident victims with direct, immediate support. When presenting materials at a public hearing on an accident, the FAA must use plain language that the distraught family members can easily understand. The agency must not use technical jargon and other bureaucratic gibberish to try and deflect blame for accidents and potentially confuse grieving family members. [15] Congress and the public must hold individual FAA executives directly responsible for their actions.

\subsection{Emergency Flight Displays and Alerts Need to be Intuitive and Helpful.}

The agency needs to overhaul its certification approach for the pilot/aircraft interface and focus on the behavior of displays and audible alarms during a variety of emergency conditions. In my opinion, merely accepting display systems that have been previously installed on other aircraft as acceptable in new or modified aircraft is unreasonably risky. Also, just having one discipline, like pilots, own the display reviews without significant input from software, and other disciplines do not guarantee an adequately evaluated certification process. Some emergency scenarios may be apparent from the aircraft FHA, PSSA, and SSA. Failures should be simulated in cockpit displays and tested as part of the certification program.

Dr. Javier de Luis of MIT's aeronautics department emailed, the "FAA has no clue how to handle software. In a meeting I had with them, I told them that they treated the Indonesian crash as if it had a simple cause and effect narrative which could be mitigated by telling pilots to pop the circuit breakers for MCAS. They failed to recognize it as a system-level failure, which caused not only the horizontal stabilizer to pitch down, but also produced alarms, alerts, faulty airspeed indications, and a host of other effects that completely overwhelmed the pilots. Any first-year graduate student in a software-safety design class would have seen it for what it was. The FAA was clueless, and basically just followed Boeing's lead." [15] Dr. de Luis is referencing the Boeing 737 Max certification program before its two catastrophic software-induced accidents. 
During emergencies, pilots may be forced to flip through paper copies of a flight manual to try to find references that would allow them to solve pathological scenarios. I have heard that pilots died with open copies of the flight manuals in their laps. [52] Pilots are then blamed for the vast majority of the accidents. Requiring pilots to memorize every erudite niche of a flight manual is unreasonable, especially when supplements frequently update the manuals. Interfaces need to be intuitive and helpful at all times, especially during unexpected flight conditions. Tucking every new gambit into some corner of an already extensive flight manual and thereby declaring a related problem solved is counterproductive. The agency must be required to make substantial changes in reviewing cockpit flight displays and audible warnings. Reviews by organizations independent of both the FAA and industry must ensure the changes happen and stick.

\subsection{Take Responsibility, do not Blame the Pilots}

The Irish Coast Guard accident of Subsection 2.3 can be viewed as a requirements failure. Enact regulations requiring navigation systems alert pilots that they must be at minimum altitudes based on terrain and airspeed. Ensure that these new software regulations are implemented as program safety requirements. The pilot must be required to override these safety alerts and interlocks to fly unnecessarily low and fast, especially if the terrain database does not have verified, reliable data. It is all too common for the F.A.A. to blame accidents on pilots instead of questioning the vehicle user interface.

\subsection{Public Oversight Requires Improved Public Education}

Perhaps the most fundamental improvement to aviation oversight is to ensure reliable and consistent U.S. national public education. The U.S. public needs to be capable of understanding the complexities of software so that they can infer the importance of supporting credible and effective aviation supervision. At the moment, it is clear that our elective representatives do not fully understand our mission. Meetings of the U.S. House transportation committees reveal clear misunderstandings by their members' questions during their hearings. Expand public education to include a standardized national course on civics that emphasizes the role of citizens in the operation and oversight of government.

\subsection{Regulators are not Independent from Management/Industry}

As a regulator, if I need to appeal to an external organization for assistance, I can only contact my federal House representative and my two Senators. These three officials are continually diverted to a wide variety of governance problems and do not have time to be bothered by individual constituents.
U.S. Federal representatives continuously raise capital for their next re-election run. Large industries with significant capital are lobbying incessantly to have their needs satisfied. Trying to get the attention of elected officials even after multiple vehicles crashes with hundreds of fatalities does not create an appealing re-election story. Once management and the aviation industry have successfully dismantled the U.S. whistle-blower programs, regulators can mostly be stifled into watching their fears of fatal accidents grow into depressing realities. Honest U.S. regulators need protection and direct avenues to warn the flying public, journalists and elected officials of likely failures.

\subsection{Managers and Regulators Must be Directly Liable}

Aviation regulators and especially their managers must be legally responsible for the consequences of their actions. U.S. representatives and journalists both tend to hold industry accountable during accident investigations without exploring the failures of the U.S. regulators and government managers who did not provide adequate oversight. Taxes fund regulator salaries. Regulators must not be paid to facilitate business opportunities. We are paid to protect the public by ensuring that products contain basic safety features and protections. Before the recent Boeing 737 Max accidents, $[17,32,35]$ regulators were diverted to help Boeing create and file needed regulatory paperwork. These tasks that Boeing company employees should have accomplished instead distracted regulators from providing essential supervision to aircraft development. Worse, Freedom of Information Act (FOIA) requests on the Boeing 737 Max accident were frozen by the Trump administration, denying the U.S. public access to the details of the malfeasance perpetrated by both Boeing and U.S. government management that directly led to fatal accidents. [22]

Regulators must be personally legally liable for their work. Managers must be directly liable for the work of each of their employees. Managers must be educated and certified to supervise the engineering disciplines of their employees. Many unqualified managers in the F.A.A. lack academic degrees in the engineering disciplines they manage. The U.S. government and its managers need to be held directly accountable for their contributions to the 737 Max oversight failures and the resulting fatalities due to criminal negligence. The following changes in federal policy need to be advanced to protect U.S. democracy:

- End sovereign immunity for U.S. Federal managers. U.S. managers must personally and directly face financial and legal consequences. They must be held individually accountable. [13]

- U.S. public funds must not be used to defend Federal officials facing charges of neglecting their public duties and criminal behavior. 


\subsection{Engineering Continuing Education and State Board Certification}

From my current vantage point, requiring U.S. regulators and engineering managers to be state board certified and be licensed engineers could be beneficial. Requiring annual or semi-annual continuing engineering education classes from accredited sources, specifically university engineering schools, should also be mandatory. Federal managers must have academic degrees from accredited universities in the engineering discipline they manage. The requirement is especially critical for the software discipline. A whole new class of government-funded engineering research centers that develop transportation innovations and perform academic quality and peer-reviewed research would both create jobs and advance technology.

\subsection{Nepotism is not a Job Perk}

Nepotism and inappropriate hiring practices give lucrative jobs to unqualified candidates while gutting regulatory enforcement of existing laws. Time card fraud and other fundamental failures weaken the regulatory process. As one of the few PhDs in Computer Science and Engineering at the F.A.A., my concerns are ignored. The children of managers with a limited academic background are advanced to decision making leadership positions where they collude with company executives to deregulate the aviation industry. Government managers often hold $\mathrm{PhDs}$ in disdain, especially if the $\mathrm{PhDs}$ are not white, Christian males. There is a contempt for science and individuals who strive to follow sound principles and a scientific method. [8, 19, 41] Given the current administration, that should not be surprising. Many of the managers were not selected for their engineering or academic accomplishments. They were selected for their strong conservative political beliefs. Both hiring and promotion practices need to be overhauled and investigated by external law enforcement.

\subsection{Free, Open-Source Software Required for Safety}

Another potential solution that could improve U.S. aviation is the introduction of an open-source Aircraft Vehicle Management System (AVMS). If aircraft are viewed as a system of components and resources, a general structure for an open-source and free AVMS could be developed. The AVMS, like an operating system kernel, could be customized to fit into different vehicles based on the hardware drivers, modules, and other customizable components that are incorporated into specific implementations. The free, open-source AVMS would help standardize avionics software and ensure that some required functionality is incorporated into aircraft systems. The shared central resource could help debug and secure aircraft software, reduce development expense, and improve the resulting safety and oversight of the product.

\section{Conclusion}

In general, the F.A.A. and the U.S. civil service need a robust external review and modifications to repair their ability to provide industry stewardship. Software certification calls out for particular attention. This paper intends to foster a dialog and open a conversation on advancing software regulatory oversight objectives.

\subsection{Public Oversight Required}

Software certification for aviation safety-critical applications needs significant external stewardship from academics. The field is woefully neglected by the U.S. F.A.A. due in part to the current U.S. political climate and from a preponderance of inappropriate industry influence. Correcting the current situation would produce both jobs and expertise that the U.S. economy and aerospace field lack. If the U.S. hopes to maintain a leading role in the international aviation field, funds and supervision into this key discipline are required. The paper has proposed specific suggestions in Section 6 to improve U.S. aviation software supervision and the agency charged with the software oversight task.

\subsection{Regulators Intentionally Distracted by Metrics and Paperwork}

At audits, software regulators spend time mechanically tracing paths through from requirements to verification tests and back as described in Subsection 3.8. Software auditors are also required to log their work in various locations to redundantly collect metrics on their projects, progress, project types, and other repetitive data points. We are given distractions that prevent us from actually reviewing code implementations, architecture, algorithms and heuristics, and other much more relevant concerns. We are subjected to bloated and redundant training that wastes days and months of our schedule. Attorneys and managers with no software background, override technical decisions regarding software airworthiness directives. We are told not to "deep dive" when reviewing software programs. As regulators, we are told not to delay the certification applicant's project timeline and the start of their anticipated revenue stream. The agency, not just the applicant, puts roadblocks and diversions in the path of real safety concerns. The department's real goal is to advance aviation commerce, not safety. Meanwhile, mechanically tracing repeatedly at software audits burns valuable time preventing a comprehensive review. Auditors also have no recourse with real consequences when certification applicants intentionally interfere in our reviews. If the applicant is dissatisfied with our progress, we are replaced by our management. If public safety is a priority, real, significant changes are required to 
remove the corruption and improve the educational background, quality, and unfettered access of the software regulators.

\subsection{Summary}

The paper started with an introduction to describe the importance of software regulation and why the topic is germane to software research organizations and essential to the public. Next, the paper demonstrated that software-related accidents and incidents are not rare. Problems occur too frequently, and the paper describes two specific examples in detail. Section 3 described the F.A.A.'s current approach to software certification. This section touched on F.A.A. policy and guidance related to software compliance. Section 4 described significant concerns with the F.A.A.'s training for software certification engineers. Section 5 described the U.S. Code of Federal Regulations that lacks software laws. Section 6 describes some potential areas and implementable changes to improve safety-critical software certification. Finally, Section 7 ends the paper with some conclusions.

\section{References}

[1] Miron Abramovici, Ytzhak H. Levendel, and Premachandran R. Menon. 1983. A Logical Simulation Machine. IEEE Transactions on Computer-Aided Design of Integrated Circuits and Systems CAD-2, 2 (April 1983), 82-94.

[2] Air Accidents Investigation Branch, Department for Transport 2005. AAIB Bulletin S1/2005 Special. Air Accidents Investigation Branch, Department for Transport, Farnborough House, Berkshire Copse Road Aldershot, Hants GU11 2HH, UK. AAIB Bulletin No: S1/2005 Ref: EW/C2005/02/03 Category: 1.1.

[3] Air Accidents Investigation Branch, Department for Transport 2006. AAIB Bulletin S3/2006 Special. Air Accidents Investigation Branch, Department for Transport, Farnborough House, Berkshire Copse Road Aldershot, Hants GU11 2HH, UK. AAIB Bulletin No: S3/2006 G-EUOB Ref: EW/C2005/10/05 Category: 1.1.

[4] Cary Aspinwall, Ariana Giorgi, and Dom DiFurio. 2019 Several Boeing 737 Max 8 pilots in U.S. complained about suspected safety flaw. The Dallas Morning News https://www.dallasnews.com/business/airlines/2019/03/12/severalboeing-737-max-8-pilots-in-u-s-complained-about-suspected-safetyflaw/.

[5] Press Association. 2019. Reform is still needed nearly three years after Rescue 116 crash, warns pilots' group. https://www.thejournal.ie/rescue-116-irish-coast-guard-4949932Dec2019/.

[6] Australian Government Australian Transport Safety Bureau (ATSB) 2007. In-flight upset event $240 \mathrm{~km}$ north-west of Perth, WA Boeing Company 777-200, 9M-MRG 1 August 2005 (final ed.). Australian Government Australian Transport Safety Bureau (ATSB), PO Box 967, Civic Square ACT 2608. Aviation Occurrence Report 200503722, Mar2007/DOTARS 50165.

[7] Daniel Brown. 2018. These are the 20 defense companies donating the most money to American politicians. Business Insider https://www.businessinsider.com/the-top-20-defense-companiesdonating-the-most-cash-to-us-politicians-2017-11?op=1.

[8] James Bruno. 2020. The Republicans' Disdain for Science Has Endangered Us All. The Washington Monthly.

[9] Margaret Burnett, John Atwood, Rebecca Walpole Djang, James Reichwein, Herkimer Gottfried, and Sherry Yang. 2001. Forms/3: A firstorder visual language to explore the boundaries of the spreadsheet paradigm. fournal of Functional Programming 11, 2 (2001), 155-206.

[10] Margaret M. Burnett. 1993. Types and Type Inference in a Visual Programming Language. In Proceedings 1993 IEEE Symposium on Visual Languages. IEEE, Bergen, Norway, 238-243.

[11] Margaret M. Burnett and Allen L. Ambler. 1994. Interactive Visual Data Abstraction in a Declarative Visual Programming Language. fournal of Visual Languanges and Computing 5, 1 (1994), 29-60.

[12] Margaret M. Burnett, Marla J. Baker, Carisa Bohus, Paul Carlson, Sherry Yang, and Pieter van Zee. 1995. Scaling Up Visual Programming Languages. Computer 28 (March 1995), 45-54. https://doi.org/10.1109/2.366157

[13] Erwin Chemerinsky. 2001. Against Sovereign Immunity. The Stanford Law Review 35, 1201 (May 2001), 1201-1224.

[14] U.S. Supreme Court. 1984. United States v. Varig Airlines, 467 U.S. 797 (1984). Number 82-1349. Certiorari to the United States Court of Appeals for the Ninth Circuit, 1 1st St NE, Washington, DC 20543. Argued January 18, 1984, Decided June 19, 1984.

[15] Javier de Luis PhD. 2020. Re: Graziella De Luis, Ethiopian 737 Max Accident. private communications - email. Lecturer, Dept. of Aeronautics and Astronautics, MIT. Dr. de Luis' sister, Graziella de Luis, was on board the Ethiopian Flight 302 Boeing Max 737 when the aircraft crashed on March 10, 2019. As a U.S. citizen, she was living in Rome and working for the U.N.

[16] Steve Denning. 2019. How Politics Delayed A Boeing Fix And Endangered Public Safety. Forbes https://www.forbes.com/sites/stevedenning/2019/03/13/howpolitics-hindered-a-boeing-fix-and-endangered-publicsafety/\#5d0bb653620c.

[17] Ian Duncan. 2019. FAA leadership disputes watchdog's finding that 737 Max inspectors were underqualified, denies misleading Congress. The Washington Post (September 2019).

[18] Paul Farrell. 2017. Preliminary Report Accident, Sikorsky S-92A, EI-ICR, Black Rock, Co. Mayo, Ireland, 14 March 2017. Preliminary Accident Report AAIU Report No: 2017-006, State File No: IRL00917016. Air Accident Investigation Unit, Department of Transport Tourism and Sport, 2nd Floor, Leeson Lane, Dublin 2, Ireland.

[19] Lisa Friedman and Brad Plumer. 2020. Trump's Response to Virus Reflects a Long Disregard for Science. New York Times, A version of this article appears in print on April 29, 2020 , Section A, Page 1 of the New York edition with the headline: Science Speaks (But President Rarely Listens).

[20] John Fritze. 2019. 737 Max maker Boeing spent more than $\$ 753,000$ on candidates, political organizations last month: FEC report. USA TODAY.

[21] L. Geppert. 2004. Lost Radio Contact Leaves Pilots on Their Own. IEEE Spectrum 41, 11 (2004), 16-17.

[22] Harry A. Hammitt (Ed.). 2019. Washington Focus. Access Reports, Vol. 45. June 26, 2019 The EPA published revisions to its FOIA regulations June 26 without going through the notice and comment period required under the Administrative Procedure Act. The new provisions allow political appointees to make decisions on FOIA releases, including whether records are covered by an exemption, are non-responsive to the request, or do not exist...

[23] Elan Head. 2017. Rescue 116 helicopter struck island that wasn't in terrain warning database. https://www.verticalmag.com/news/rescue116-helicopter-struck-island-wasnt-terrain-warning-database.

[24] Mark Huber. 2017. Irish S-92 Accident Report Paints Picture of Confusion. AINOnline https://www.ainonline.com/aviationnews/business-aviation/2017-05-16/irish-s-92-accident-reportpaints-picture-confusion.

[25] FAA Leadership \& Learning Institute. 2018. (01249) Influence, Inquiry \& Implications: Leaders Path to the Future. Embassy Suites by Hilton Tampa USF Near Busch Gardens, 3705 Spectrum Blvd, Tampa, FL 33612. 
[26] Daniel Jackson. 2009. A Direct Path to Dependable Software https://doi.org/10.1145/1498765.1498787. Commun. ACM 52, 4 (April 2009), 78-88. https://doi.org/10.1145/1498765.1498787

[27] Daniel Jackson, Martyn Thomas, and Lynette I. Millett (Eds.). 2007. Software for Dependable Systems: Sufficient Evidence? National Academies Press online, The National Academies Press 500 Fifth Street, N.W. Washington, DC 20001. ISBN: 0-309-66738-0, Committee on Certifiably Dependable Software Systems Computer Science and Telecommunications Board, Division on Engineering and Physical Sciences.

[28] Thomas Kaplan. 2019. After Boeing Crashes, Sharp Questions About Industry Regulating Itself. New York Times https://nyti.ms/2CGfRxR.

[29] Peter Bernard Ladkin. $1998 . \quad$ Abstracts of References and Incidents. http://www.rvs.unibielefeld.de/publications/Incidents/DOCS/FBW.html. University of Bielefeld - Faculty of technology.

[30] Prof. Peter Bernard Ladkin. 1994. Report on the Accident to Airbus A320-211 Aircraft in Warsaw on 14 September 1993. Technical Report. Universität Bielefeld, AG Rechnernetze und Verteilte Systeme, Technische Fakultät, Universität Bielefeld, Universitätsstraße 25, D-33615 Bielefeld, Germany. Main Commission Aircraft Accident Investigation Warsaw.

[31] Michael Laris, Lori Aratani, Josh Dawsey, and Toluse Olorunnipa. 2019. FAA doubles down on decision not to ground the Boeing 737 Max, as counterparts around the world have done. The Washington Post - https://wapo.st/3iFtAqI.

[32] Alec MacGillis. 2019. The Case Against Boeing. The New Yorker and ProPublica (18 November 2019), 29. Published in the print edition of the November 18, 2019.

[33] David G. McCullough. 2015. The Wright brothers (first ed.). Number ISBN 9781476728742. Simon and Schuster, New York, NY

[34] S.A. McLeod. 2007. The Milgram experiment. Retrieved from www.simplypsychology.org/milgram.html.

[35] Ian Duncan Michael Laris and Lori Aratani. 2019. FAA's lax oversight played part in Boeing 737 Max crashes, but agency is pushing to become more industry-friendly. The Washington Post (October 2019). Oct. 28, 2019 .

[36] Stephen Mihm. 2019. The FAA has always been cozy with the aviation industry. That's why we need to empower the NTSB. Los Angeles Times https://www.latimes.com/business/la-fi-faa-ntsb-boeing737-crash-20190322-story.html.

[37] Stanley Milgram. 1963. Behavioral Study of Obedience. Fournal of Abnormal and Social Psychology 67, 4 (Nov 1963), 371-378.

[38] Amit Narang. 2019. Corporate self-regulation is failing. The Hill https://thehill.com/blogs/congress-blog/the-administration/436328corporate-self-regulation-is-failing.

[39] National Transportation Safety Board 2000. Aircraft Accident Report, Controlled Flight into Terrain, Korean Air Flight 801, Boeing 747-300, HL7468, Nimitz Hill, Guam, August 6, 1997. National Transportation Safety Board, Public Inquiries Section, RE-51, 490 L'Enfant Plaza, East, S.W., Washington, D.C. 20594. NTSB/AAR-00/01 PB00-910401 Notation 6952B.

[40] Laura Parker. 1987. Cheating Alleged on Air-Traffic Exam. The Washington Post - https://wapo.st/3lo372M.

[41] Ed Pilkington. 2020. Pandemic brings Trump's war on science to the boil - but who will win? The Guardian https://www.theguardian.com/us-news/2020/may/03/sciencedonald-trump-coronavirus.
[42] Radio Technical Commission for Aeronautics (RTCA) 1981. Software Considerations in Airborne Systems and Equipment Certification (rtca do-178 ed.). Radio Technical Commission for Aeronautics (RTCA), 1717 H Street, NW, Suite 655, Washington, DC 20006 USA. Prepared by: SC-145, www.rtca.org.

[43] Radio Technical Commission for Aeronautics (RTCA) 1992. DO-178B: Software Considerations in Airborne Systems and Equipment Certification (rtca do-178b ed.). Radio Technical Commission for Aeronautics (RTCA), 1828 L Street, NW, Suite 805, Washington, D.C. 20036. Prepared by: RTCA SC-167 / EUROCAE WG-12, www.rtca.org.

[44] Radio Technical Commission for Aeronautics (RTCA) 2011. RTCA/DO-178 Software Considerations in Airborne Systems and Equipment Certification, RTCA Inc. (rtca do-178c ed.). Radio Technical Commission for Aeronautics (RTCA), 115018 Street, NW, Suite 910 Washington, DC 20036-3816 USA. Prepared by: SC-205, www.rtca.org.

[45] Special Investigations (11-3) Ronald C. Engler, Director. 2012. Memorandum ACTION: OIG Investigation, \# I1OA000073SINV, Re: FAA Transport, Airplane Directorate, Seattle, W A. FOIA request. Redacted for public disclosure.

[46] RTCA, Incorporated 1998. Standards for Processing Aeronautical Data. RTCA, Incorporated, 1140 Connecticut Avenue, N.W., Suite 10, Washington, DC 20036-4001 USA.

[47] Fredreka Schouten, Ted Barrett, and Lauren Fox. 2019. Boeing a major lobbying player on Capitol Hill. CNN https://www.cnn.com/2019/03/12/politics/boeing-capitol-hilllobbying/index.html.

[48] Society of Automotive Engineers, Inc. (SAE) 1996. ARP4754 Certification Considerations for Highly-Integrated or Complex Aircraft Systems. Society of Automotive Engineers, Inc. (SAE), 400 Commonwealth Drive, Warrendale, PA 15096-0001.

[49] Society of Automotive Engineers, Inc. (SAE) 1996. SAE ARP4761 Guidelines and Methods for Conducting the Safety Assessment Process on Civil Airborne Systems and Equipment. Society of Automotive Engineers, Inc. (SAE), 400 Commonwealth Drive, Warrendale, PA 150960001.

[50] Steven Davidoff Solomon. 2010. The Governments Elite and Regulatory Capture. The New York Times https://dealbook.nytimes.com/2010/06/11/the-governments-eliteand-regulatory-capture/?searchResultPosition $=1$.

[51] Emma Stodder. 2019. Corrupted Oversight: The FAA, Boeing, and the 737 Max. Pogo https://www.pogo.org/analysis/2019/10/corruptedoversight-the-faa-boeing-and-the-737-max/.

[52] Gwyn Topham. 2019. Lion Air pilots were looking at handbook when plane crashed. The Guardian https://www.theguardian.com/world/2019/mar/20/lion-air-pilotswere-looking-at-handbook-when-plane-crashed.

[53] U.S. Department of Transportation Federal Aviation Administration 2018. ORDER 8110.49A Software Approval Guidelines (8110.49a ed.). U.S. Department of Transportation Federal Aviation Administration. https://rgl.faa.gov/.

[54] Eva Wall. 2020. Pilots' organisation expresses concern that tragic Coast Guard helicopter crash could happen again. https://extra.ie/2020/01/05/news/irish-news/pilots-organisationcoast-guard-helicopter-crash.

[55] Andrew Weir. 1999. The Tombstone Imperative The Truth About Air Safety. Simon \& Schuster. ISBN 0-684-81993-7. 